\title{
Potential Health Benefits of Thai Seasonal Fruits; Sapodilla and Star Fruit for Elderly People
}

\author{
Jirakrit Leelarungrayub*1, Yothin Pothasak ${ }^{1}$, Rungtiwa Kuntain ${ }^{1}$, Jynwara Kaju ${ }^{1}$ and Ahmed \\ Muhammad Izhar ${ }^{2,3}$ \\ ${ }^{1}$ Department of Physical Therapy, Faculty of Associated Medical Sciences, Chiang Mai University, Thailand \\ ${ }^{2}$ Graduate Institute of Biomedical Engineering, National Tawain University of Science and Technology, Taiwan \\ ${ }^{3}$ School of Physiotherapy, Kind Edward Medical University, Pakistan
}

*Corresponding author: Jirakrit Leelarungrayub, Department of Physical Therapy, Faculty of Associated Medical Sciences, Chiang Mai University, Chiang Mai, Thailand

To Cite This Article: Jirakrit Leelarungrayub. Potential Health Benefits of Thai Seasonal Fruits; Sapodilla and Star Fruit for Elderly People. Am J Biomed Sci \& Res. 2019 - 5(1). AJBSR.MS.ID.000873. DOI: 10.34297/AJBSR.2019.05.000873

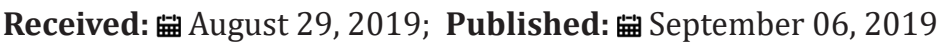

\begin{abstract}
Nowadays, the proportion of geriatric population has been increased around the world, and likewise has been increased in Thailand. The aged population have high risks of low-immunity and high oxidative stress, which is related to chronic diseases such as; hypertension, stroke, cardiac diseases, diabetics, and cancer. In Thailand, there are many valuable fruits such as; durian, banana, oranges, papaya, and guava, etc. In addition, there are still some seasonal fruits which have interesting useful effects but with less scientific evidences. Sapodilla and Star fruit are rare seasonal fruits that have been claimed to improve the health status with its antioxidant and anti-inflammatory effects in human body. Presently, evidences have revealed that the ripped sapodilla extract possesses the antioxidant capacity with total phenolic, retinoic acid (Vit A), and L-ascorbic acid (Vit C) and scavenging activity on superoxide radical, hydroxyl radical, hydrogen peroxide and nitric oxide (NO). It could inhibit the tumor necrotic factoralpha (TNF- $\alpha$ ). Whereas, the ripped star fruit (sour-type) extract contains the retinoic acid and L-ascorbic acid which was reported in vitro designed study. Interesting evidences in elderly persons showed that supplementation of $100 \mathrm{~g}$ of either ripped sapodilla or ripped star fruit twice a day for 4 weeks after meal could improve; total antioxidant capacity, Vit.A, and Vit.C status, the 6-minute walking distance, and reduce the nitric oxide (NO). Moreover, supplementation of ripped star fruit could reduce the TNF- $\alpha$, Low-density lipoprotein (LDL), while the ripped Sapodilla supplement reduced the cholesterol.as. Therefore, this mini review presents the health benefits of seasonal fruits, sapodilla or star fruit for health status among elderly individuals.
\end{abstract}

Keywords: Carcinogen; Nicotine; Tumor growth; Cytotoxic; Apoptosis

\section{Introduction}

Now a days, the proportion of population in aging stage has been increased around the world, and likewise, it will be increasing in Thailand from 9.0 million in 2015 to 15.9 million in 2035 [1]. The aged persons have high risks of chronic diseases such as cardiac disease, type II diabetes, hypertension or musculoskeletal disorder [2], because of low-immunity and high inflammatory status $[3,4]$. Previous evidences have proposed that the aged-related changes are associated with immune system by releasing the many cytokines such as; C-reactive protein (CRP), interleukin-6 (IL-6), interleukin-1 (IL-1), as tumor necrosis factor-alpha (TNF- $\alpha$ ) [4] in result of some complex network of cells activation from oxidants [5]. In addition, the low antioxidant status has been reported among elderly people. Prior evidences showed that the aged individuals had low glutathione (GSH) antioxidant and high oxidative stage by malondialdehyde (MDA) formation from lipid peroxidation and protein hydroperoxide $(\mathrm{PrOOH})$ releasing from protein oxidation $[6,7]$.

Oxidative stress also has been proposed in the hypertension pathology from lipid metabolism abnormality for example, low level of high-density lipoprotein-cholesterol (HDL-C) and high level of low-density lipoprotein-cholesterol (LDL-C) [8], which was successfully confirmed in a previous elderly people study [9]. In addition, the function of HDL-C is still to promote the cholesterol effusion and inhibit the oxidation of LDL from free radicals [9]. In addition, previous information claimed that low status of LDL oxidation could reduce the releasing of pro-inflammatory mediators from macrophages and reduce adhesion molecule expression on the endothelial cells as nitric oxide synthase (NOS) in order to release the NO [10]. The especially interesting reviews have been documented that high chronic oxidative stress or 
prolonged free radical releasing may result in decreased muscle strength, endurance and function capacity $[11,12]$. Unfortunately, there is not any evidence completely indicating or explaining that why the free radicals reduced the muscle strength and endurance in human. But, a basic theory of muscle fatigue is "an exercise-induced reduction in muscle force generation" has been proposed $[13,14]$. There are various potential mechanisms by which NO and ROS might influence skeletal muscle force production, affecting calcium regulation, and/or myofilament function. Possibly, high NO can reduce adenosine triphosphate (ATP) production, by inhibition the activity of glyceraldehyde-3-phosphate dehydrogenase $[15,16]$ and creatinine kinase [17] that could limit ATP production. Moreover, high levels of free radicals also inhibited the sarcoplasmic reticulum (SR) calcium APTase (SERCA) activity [18,19], especially high amount of NO inhibits ryanodine activity and retards calcium release [20,21]. Overall evidences indicate the relationship of oxidative stress and inflammation on physical function in elderly population, therefore extra-supplements such as; nutrients, foods, or natural fruits, can be enhanced in among elderly persons.

\section{Functional Food for Health}

Now a days, the functional foods containing various nutrient components has been promoted for example; grape peel, green peppers, garlic, onions, vegetables, and fruit juice containing various antioxidant vitamins, and natural phenolics [22]. Especially L-ascorbic acid (Vit C) has potential to enhance the immune system $[23,24]$, in elderly subjects [25]. Moreover, the flavonoids in the aqueous or lipophilic phases in many fruits, vegetables and red wine also have antioxidant property [26]by scavenging free radicals [27]. Moreover, previous review has been concluded that prenylated phenolics have various effects on inhibition of the cyclooxygenases and lipoxygenases activity, and releasing of mediators from neutrophils, mast cells and macrophages [28]. These cells play a vital role in the initiation of inflammatory response by the production of pro-inflammatory mediators as prostaglandin E2 (PGE2) and cytokines as interleukin 6 (IL-6) and tumor necrosis factor-alpha (TNF- $\alpha$ ) [29]. Previous report has been confirmed that polyphenols curcumin and epigallocatechin gallate have essential role in immunity by interfering with pro-inflammatory cytokine synthesis, immune cell regulation, and gene expression [30]. Thus, natural fruits containing various polyphenols and antioxidant vitamins have antioxidant, anti-inflammatory activities and modulate immune function that possibly have potential effects on health in elderly people.

\section{Sapodilla (Manikara zapota L)}

Sapodilla is one of many fruits in Thailand, which has sweet taste after ripe. It has classified as Achras Zapota, or the scientific name of Manilkara zapota Less. It is native to Mexico and Central American [31], and as a fruit tree across tropical and subtropical America, the West Indies, India and Thailand $[32,33]$. Sapodilla fruit has a sweet taste when ripe and small size of 4-8 cm in diameter with ellipsoid or round shape (Figure 1). The nutritional composition and scientific evidence have not been reported. But, the information of nutrients for standard reference of ripe sapodilla in the United States Database from Department of Agriculture in 2015, represented that $100 \mathrm{~g}$ of sapodilla comprises carbohydrates (19.96 g), vitamin C (14.7 mg), and vitamin A (3 $\mu$ g) with $83 \mathrm{Kcal}$ of total energy [34]. The benefits on human health has been reported in some reports or studies; for example, the leaves can be used to treat cough, cold, anti-diarrheal, antibiotic, anti-hyperglycemic, and hypo-cholesterol [35]. Previous evidences indicated the Sapodilla has antioxidant activity with polyphenols, especially gallocatechin or catechin, methyl-4-0-galloylchlorogenate and 4-0-galloylchlorogenic acid after methanolic extracted [36]. Unfortunately, there are not any scientific evidences on supplementation of fresh Sapodilla fruit in human. Whereas, ripped sapodilla also is popular and consumed in elderly people because of its flavor and sweet taste in Thailand. Presently study of Leelarungrayub and co-worker (2019) showed that sapodilla extract that was prepared after fine homogenized with a motor blender had 1.89 \pm 1.09 ?g equivalent to standard gallic acid of total phenolic in one gram, as well as $4.87 \pm 0.98$ ? $\mathrm{g}$ of Vit A and $13.05 \pm 2.65 \mu \mathrm{g}$ of Vit C in 100 grams of sapodilla extract. Moreover, sapodilla extract also had scavenging activity on superoxide radicals, hydroxyl radicals, hydrogen peroxide and nitric oxide. In addition, it still inhibited the TNF- $\alpha$ releasing from peripheral blood mononuclear cells (PBMC) in vitro model [37].
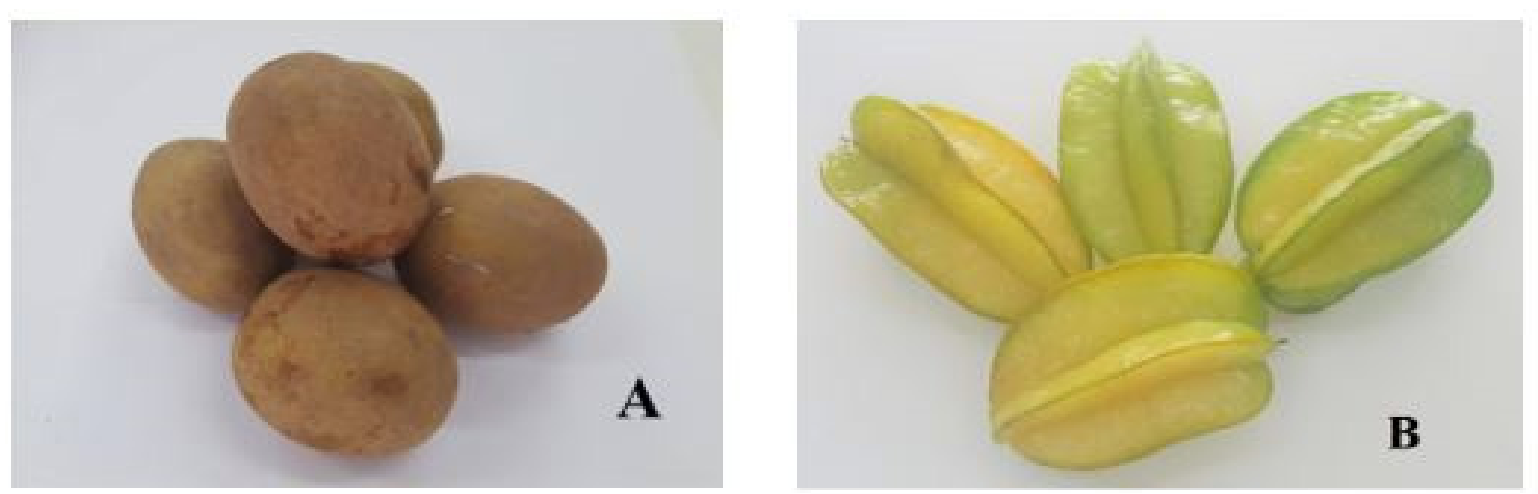

Figure 1: Sapodilla (Manilkara zapota $L$ ) (A) and Star Fruit (Averrhoa carambola L) (B). 
The fresh sapodilla fruit supplement health benefits on elderly population has been confirmed at 100 grams after meal twice a day for 4 weeks, the results showed the improvement on total antioxidant capacity (TAC), as well as reduced the malondialdehyde (MDA) and NO levels significantly. Finally, the anti-oxidative results from supplement of fresh sapodilla fruit, has been confirmed by significant increases of Vit. A and Vit. A in plasma. But no difference was noted in plasma level of TNF- $\alpha$. However, supplementation of sweet sapodilla should be concerned among diabetic or hyperglycemic elderly persons, because of high level of glucose in sapodilla fruit. There was interesting data of physical performance among elderly subjects, which showed significant increases of 6-minute walking [37]. Possibly, health benefits of supplementation the fresh sapodilla were mainly antioxidant activity, but no antiinflammatory activity among healthy elderly people. Whereas, the mechanism of walking endurance improvement is still unclear, whether it involved the NO pathway or glucose utilization that should be confirmed in the future. Moreover, to recheck the immune modulatory function of Sapodilla fruit, that is very challenging and more studies in the future are required.

\section{Star Fruit (Averrhoa carambola $L$ )}

Now a days, there are two types of star fruit, sweet or sour. It is one of the many native fruits grown in all over Thailand, as well as in Taiwan, Indonesia, India, Sri Lanka, etc. Typical characteristics of the star fruit are five -pointed cross section forming a star, green to yellowish skin, when ripped [38]. The previous data has reported various beneficial effects on human health such as antipyretic, laxatives, appetite stimulants, diuretics and digestive agent, also including treatment of; throat inflammation, mouth ulcers, toothache, cough, asthma and eye related problems $[39,40]$. Previous study has revealed the benefits of star fruit on suppression of the glycation and reduced glycohemoglobin in all proteins in aging population [41] Unfortunately, the mechanisms on that results were not confirmed and evaluated. Its bioactive compounds have been proposed with natural compounds such as saponins, alkaloids, flavonoid C-glycosides and tannin [42,43], especially L-ascorbic acid (Vit C) [44]. How different are bioactive compounds of sour and sweet types of star fruit in Thailand? It is still unconfirmed. But a previous study reported the high Vit. C $(1.71 \pm 0.5 \mathrm{mg})$ in sour-type star fruit extract at 100 grams and low Vit. A concentration $(0.2 \pm 0.00 \mu \mathrm{g})$ [45]. The updated evidence showed the beneficial effects on elderly people from supplement of fresh star fruit juice at 100 grams for twice a day after meal for 4 weeks, by increasing TAC, Vit C, Vit A, as well as reduction of MDA and PrOOH in plasma $[45,46]$. Moreover, supplementation of fresh star fruit also helped to increase the HDL-C and reduced the LDL-C in elderly serums [45]. Interesting results documented on reduced NO, TNF- $\alpha$, interleukin-23 levels when supplemented for 4 weeks, as well as the 6-minute walking distance among elderly subjects [46]. Therefore, possibly it is claimed that star fruit has antioxidant and anti-inflammatory activities with its mainly bioactive compound of Vit.C. Previous data has been confirmed that TNF- $\alpha$ and IL-23 are the pro-inflammatory cytokines that released from macrophage cells [47], it may involve the many auto-immune diseases as psoriatic skin disease and ankylosing spondylitis [48]. The mechanisms of the star fruit on improvement on the walking endurance is still unclear because of no evidences of nutrients in star fruit, either glucose or fat contents in fresh star fruit, but the activity on antioxidant related with anti-inflammatory is possibly can be proposed. That is consistency with some previous data that claimed the low muscle strength, endurance and functional capacity when high oxidants and low antioxidant status were presented [49,50]. However, all mechanism hypothesis should be confirmed and evaluated in the future. Moreover, consumption of the fresh star fruit also should be concerned because of high oxalic acid content that will effect on the kidney functions in elderly persons who has renal dysfunction, uremic conditions [51], or chronic kidney disease [52].

\section{Conclusions and Suggestion}

Seasonal fruits as Sapodilla and Star fruit either grown in Thailand or any other countries have potential benefits for people, especially elderly people. Consumption of fresh fruits or drinking fresh juices after meal should include in routine. Although, literature have few evidences to refer its efficiency in human life, but they are classified in the natural fruits that can be consumed in many countries. Important recommendation that recently published by WHO/FAD claimed that a minimum of 400 grams of fruits and vegetables per day can prevent the chronic disease such as heart disease, cancer, diabetes and obesity [53], whereas a previous recommendation on dietary pattern following the American Heart Association/American College of Cardiology (AHA)/ACC) Guidelines for the healthy US-style eating pattern, unsweetened fruit was 1 cup of fruit or $1 / 2$ cup of fruit juice or $1 / 3$ cup of a fruit juice blend can be used [54]. Although, the sapodilla or star fruits that applied in Thai elderly subjects were approximately 3-5 servings or equivalent to 100 grams per meal, that was higher than the previous recommendation only 3-5 serving in Thai Dietary Guidelines for Thai People (2001) [55]. But a previous data indicated that people over the age of 50 years should intake higher number of servings (more than 5 servings per day) than younger adults [56]. Therefore, this review suggested that consumption of the seasonal fruits as sapodilla or start fruit which have antioxidant and antiinflammatory activities in elderly people, at 5-10 servings per day or 5 servings per meal in morning or in evening will enhance the health status for elderly people.

\section{References}

1. (2006) Institute Population and Social Research Mahidol University Population projection for Thailand 2005-2025 (1st) Mahidol University, Thailand. 
2. Fontana L (2009) Modulating human aging and age-associated diseases Biochim Biophys Acta 1790(10): 1133-1138.

3. Michaud M, Balardy L, Moulis G, Gaudin C, Peyrot C, et al. (2013) Proinflammatory cytokines, aging, and aged -related diseases. Journal of the American Medical Directors Association 13: 877-882.

4. Singh T, Newman AB (2011) Inflammatory markers in population studies of aging. Ageing Res Rev 10(3): 319-329.

5. Hughes DA (1999) Effects of dietary antioxidants on the immune function of middle-aged adults. Proc Nutr Soc 58(1): 79-84.

6. Junqueria VCB, Barros SBM, Chan SS, Rodrigues L, Giavarotti L, et al. (2004) Aging and oxidative stress. Molecular Aspects of Medicine 25(12): 5-16.

7. Mezzetti A, Lafenna D, Romano F, Costantini F, Pierdomenico SD, De Cesare D, et al. (1996) Systemic oxidative stress and its relationship with age and illness. Associazone Medica "Sabin". Journal of the American Geriatrics Society 44(7): 823-827.

8. Kumar A (2014) Correlation between anthropometric measurement, lipid profile, dietary vitamins, serum antioxidants, lipoprotein (a) and lipid peroxides in known case of 345 elderly hypertensive South Asian aged 56-64 y-A hospital-based study. Asian Pac J Trop Biomed 4(1): S189-S197.

9. Holzer M, Trieb M, Konya V, Wadsack C, Heinemann A, et al. (2014) Aging affects high-density lipoprotein composition and function. Biochim et Biophysica Acta 1831(9): 1442-1448.

10. Bursill CA, Lastro ML, Beattie DT, Nakhla S, van der Vorst E, et al. (2010). High-density lipoproteins suppress chemokines and chemokine receptors in vitro and vivo. Arterosclerosis, Thrombosis, and Vascular Biology 30(9): 1773-1778.

11. Gianni P, Jan KJ, Douglas MJ, Stuart PM, Tarnopolsky MA (2004) Oxidative stress and the mitochondrial theory of aging in human skeletal muscle. Experimental Gerontology 39(9): 1391-1400.

12. Rynan MJ, Dudash HJ, Docherty M, Geronilla KB, Baker BA, et al. (2008) Aging-dependent regulation of antioxidant enzymes and redox status in chronically loaded rat dorsiflexor msucles. J Gerontol A Biol Sci Med Sci 63(10): 1015-1026.

13. Gandevia SC (2001) Spinal and supraspinal factors in human muscle fatigue. Physiology Review 81(4): 1725-1789.

14. Westerblad H, Allen DG, Lannergren J (2002) Muscle fatigue: lactic acid or inorganic phosphate the major cause? News in Physiological Sciences 17: 17-21.

15. Mohr S, Stamler JS, Brune B (1996) Posttranslational modification of glyceraldehyde-3-phosphate dehydrogenase by S-nitrosymlation and subsequent NADH attachment. J Biol Chem 271(8): 4209-4214.

16. Molina y Vedia L, MaDonald B, Reep B, Brune B, Di Silvio M, et al. (1992) Nitric oxide-induced S-nitrosylations of glyceraldehyde-3-phosphate dehydrogenase inhibits enzymatic activity and increases endogenous ADP-ribosylation. The Journal of Biological Chemistry 267(35): 2492924932.

17. Gross WL, Bak MI, Ingwall JS, Arstall MA, Smith TW, et al. (1996) Nitric oxide inhibits creatine kinase and regulates rat heart contractile reserve. Proc Natl Acad Sci USA 93(11): 5604-5609.

18. Gutierrez-Martin Y, Martin-Romero FJ, Inesta-Vaquera FA, Gutierrez-Me rino C, Henao F (2004) Modulation of sarcoplasmic reticulum Ca2+-ATPase by chronic and acute exposure to peroxynitrite. European Journal of Biochemistry 271(13): 2647-2657.

19. Hansen JM, Go YM, Jones DP (2006) Nuclear and mitochondrial compartmentation of oxidative stress and redox signaling. Annu Rev Pharmacol Toxicol 46: 215-234

20. Hart JD, Dulhunty AF (2000) Nitric oxide activates or inhibits skeletal muscle ryanodine receptors depending on its concentration, membrane potential and ligand binding. J of Membr Biol 173(3): 227-236.
21. Henunks LM, Gachiels HA, Dekhuijzen PN, Prakash YS, Sieck GC (2001) Nitric oxide affects sarcoplasmic calcium release in skeletal myotubes. Journal of Apply Physiology 91: 2117-2124.

22. Ferrari CK (2007) Functional foods and physical activities in health promotion of aging people. Maturitas 58(4): 327-339.

23. Podmore ID, Griffiths HR, Herbert KE, Mistry N, Mistry P, et al. (1998) Vitamin C exhibits pro-oxidant properties. Nature 392(6676): 559.

24. Lopez-Varela S, Gonzalez-Gross M, Marcos A (2002) Functional foods and the immune system: A review. European Journal of Clinical Nutrition 56(3): S29-S33.

25. Kennes B, Dumont I, Brohee D, Hubert C, Nerve P (1983) Effect of vitamin C supplementation on cell-mediated immunity in old people. Gerontology 29(5): 305-310.

26. Rive-Evans C, Miller N, Paganga G (1997) Antioxidant properties of phenolic compounds. Trends in Plant Science 2(4): 152-159.

27. Huyut Z, Beydemir S, Gulcin I (2017) Antioxidant and antiradical properties of selected flavonoids and phenolic compounds. Biochemistry Research International 4(2): 152-159.

28. Brezani V, Smejkal K, Hosek J, Tomasova V (2008) Anti-inflammatory natural prenylated phenolic compounds-potential lead substances. Current Medicinal Chemistry 25(10): 1094-1159.

29. Murray PJ, Wynn TA (2011) Protective and pathogenic functions of macrophage subsets. Nat Rev Immunol 11(11): 723-737.

30. Ding S, Jiang H, Fang J (2018) Regulation of immune function by polyphenols. Journal of immunology research. ID 1264074.

31. Govaerts R (2017) World Checklist of Sapotaceae. Richmond, UK. Royal Botanic Gardens, Kew.

32. Morton JF (1987) Fruits of Warm Climates. Miami, USA. JF Morton pp. 517.

33. Mickelbart MV (1996) Sapodilla: a potential crop for subtropical climates. In: Progress in new crops: Proceedings of the Third National Symposium, Indianapolis, USA Janick J (Edt) 22-25. Alexandria, USA: American Society for Horticultural Science pp. 439-446.

34. (2018) United States Department of Agriculture (2015) USDA food composition databases. USDA National Nutrient Database for Standard Reference Legacy Release.

35. Barbalho SM, Bueno PC, Delazari DS, Ghuiguer EL, Cogueiro DP, et al. (2015) Antidiabetic and antilipidemic effects of Manikara Zapata. J Med Food 18: 385-391.

36. Ma J, Luo XD, Protiva P, Yang H, Ma C, et al. (2003) Bioactive novel polyphenols from the fruit of Manikara zapota (Sapodilla). J Nat Prod 66: 983-986.

37. Leelarungrayub J, Sriboonreung T, Pothasak Y, Kaju J, Puntumetakul R (2019) Antioxidant and Anti-inflammatory Activities of Manilkara zapota (Sapodilla) In vitro and Efficiency in Healthy Elderly Persons. Biomedical Journal of Scientific \& Technical Research.

38. O’Hare TJ (1993) Postharvest physiology and storage of carambola (star fruit): a review. Postharvest Biology and Technology 2(4): 257-267.

39. Dasgupta P, Chakrakorty P, Bala NN (2013) Averrhoa carambola: an updated review. International Journal of Pharma Research \& Review 2(7): 54-63.

40. Manda H, Vyas K, Pandya A, Singhal G (2012) A completed review on: Averrhoa carambola. World Journal of Pharmacy and Pharmaceutical Sciences 1(1): 17-33.

41. Krone CA, Ely JT (2004) Ascorbic acid, glycation, clycahemoglobin and aging. Medical Hypotheses 62(2): 275-279.

42. Thomas S, Patil DA, Patil AG, Chandra N (2008) Pharmacognostic evaluation and physiochemical analysis of Averrhoa carambola L. fruit. Journal of Herbal Medicine and Toxicology 2(2): 51-54. 
43. Yang D, Xie H, Jia X, Wei X (2005) Flavonoid C-glycosides from star frui and their antioxidant activity. Journal of Functional Foods 16: 204-210.

44. Shui G, Leng LP (2004) Analysis of polyphenolic antioxidants in star fruit using liquid chromatography and mass spectrometry. Journal of Chromatography 1022(1-2): 67-75.

45. Leelarungrayub J, Yanki A, Pinkaew D, Puntumetakul R, Laskin JJ, Bloomer RJ (2016) A prelilimary study on the effects of star fruit consumption on antioxidant and lipid status in elderly Thai individuals. Clin Inter Aging. 11: 1183-1193.

46. Leelarungrayub J, Laskin JJ, Bloomer RJ, Pinkaew D (2016) Consumption of star fruit on pro-inflammatory markers and walking distance in the community dwelling elderly. Arch Gerontol Geriatr 64: 6-12.

47. Zhou L, Ivanov II, Spolski R, Min R, Shenderov K, Egawa T, et al. (2007) IL-6 programs T(H)-17 cells differentiation by promoting sequential engagement of the IL-21 and IL-23 pathways. Nature Immunology 8(9): 967-974.

48. Yawalkar N, Tascharner GG, Hunger RE, Hassan AS (2009) Increased expression of IL-12p70 and IL-23 by multiple dendritic cell and macrophage subsets in plaque psoriasis. Journal of Dermatological Science 54(2): 99-105

49. Gianni P, Jan KJ, Douglas MJ, Stuart PM, Tarnopolsky MA (2004) Oxidative stress and the mitochondrial theory of aging in human skeletal muscle. Experimental Gerontology 39(9): 1391-1400.
50. Rynan MJ, Dudash HJ, Docherty M, Geronilla KB, Baker BA, et al. (2008) Aging-dependent regulation of antioxidant enzymes and redox status in chronically loaded rate forsiflexor muscles. J Gerontol A Biol Sci Med Sci 63(10): 1015-1026.

51. Neto MM, Cardeal da Costa JA, Garcia-Cairasco N, Netto JC, Nakagawa B, et al. (2003) Intoxication by star fruit (Averrho carambola) in 32 uremic patients: treatement and outcome. Nephrology Dialysis Tansplantation 18(1): 120-125.

52. Abeysekera RA, Wijetunge S, Nanayakkara N, Wazil AWM, Ratnatunga NVI, et al. (2005) Intoxication by star fruit toxicity: a cause of both acute kidney injury and chronic kidney disease: a report of two cases. BMC Research Notes 8: 796.

53. Promoting fruit and vegetable consumption around the world. World Health Oragnization (WHO).

54. Horn LV, Carson JAS, Appel LJ, Economos C, Karmally W, Lancaster K, et al. (2016) Recommended dietary pattern to achieve adherence to the American Heart Association/American College of Cardiology (AHA/ ACC) Guidelines.; A scientific statement from the American Heart Association. Circulation 134: e505-e529.

55. Manual Nutrition Flag: Healthy Eating for Thais. Nutrition Division, Department of Health, Ministry of Public Health. 2001.

56. Greene GW, Fey-Yensan N, Padula C, Rossi SR, Rossi JS, et al. (2008) Change in fruit and vegetable intake over 24 months in older adults: results of the SENIOR project intervention. Gerontologist 48(3): 378-387. 